\title{
Radiosurgery or hypofractionated stereotactic radiotherapy after craniospinal irradiation in children and adults with medulloblastoma and ependymoma
}

\author{
Aleksandra Napieralska ${ }^{1}$ (D) - Iwona Brąclik ${ }^{2} \cdot$ Michał Radwan $^{2} \cdot$ Marek Mandera $^{3} \cdot$ Sławomir Blamek $^{1}$
}

Received: 15 June 2018 / Accepted: 20 November 2018 / Published online: 4 December 2018

(C) The Author(s) 2018

\begin{abstract}
Purpose To assess the results and tolerance of radiosurgery/hypofractionated stereotactic radiotherapy performed after craniospinal irradiation for recurrent tumor.

Methods Fourteen patients aged 3-46 years, diagnosed with medulloblastoma (10), anaplastic ependymoma (3), and primitive neuroectodermal tumor (1). All patients had craniospinal irradiation (CSI) with the total dose of 30.6-36 Gy and boost to 53.960 Gy either during primary or during second-line treatment. Twelve patients were irradiated with a single dose of 6-15 Gy (median 14.5 Gy). One received three fractions of 5 Gy and one six fractions of 5 Gy. In statistical analysis, the Kaplan-Meier method and log-rank test were used. The overall survival was calculated from the date of the end of stereotactic radiosurgery to the date of death or last contact.

Results Recurrences were diagnosed after the median time of 16 months after the end of primary treatment. Eleven patients died during the follow-up. The follow-up for the 3 patients still alive was 6.7, 40.5, and 41.4 months, respectively. One- and 2-year overall survival (OS) was $70 \%$ and $39 \%$. Patients who had ECOG performance status of 0 at the time of diagnosis of the disease trended to have better 2-year OS compared to those evaluated as ECOG $1(p=0.057)$. Treatment results were evaluable in 12 patients. Local control (stabilization or regression of the lesion) was achieved in 9 (75\%). Overall disease progression was $67 \%$. No patient developed radiation-induced necrosis. The treatment was well tolerated and no serious adverse effects were observed. Eleven patients were given steroids as a prevention of brain edema and four of them needed continuation of this treatment afterwards. In 7 patients, symptoms of brain edema were observed during the first weeks after reirradiation.

Conclusions Stereotactic radiosurgery or hypofractionated stereotactic radiotherapy is an effective treatment method of the local recurrence after CSI and can be performed safely in heavily pre-treated patients.
\end{abstract}

Keywords Radiotherapy $\cdot$ CSI $\cdot$ Recurrence $\cdot$ Reirradiation

Aleksandra Napieralska

olanapieralska@gmail.com

1 Department of Radiotherapy, The Maria Sklodowska-Curie Institute - Oncology Center, Gliwice Branch, Ul. Wybrzeże AK 15, 44-101 Gliwice, Poland

2 Department of Radiotherapy and Brachytherapy Planning, The Maria Sklodowska-Curie Institute - Oncology Center, Gliwice Branch, ul. Wybrzeze AK 15, Gliwice 44-101, Polska

3 Department of Pediatric Neurosurgery, Medical University of Silesia, Katowice, Poland

\section{Introduction}

Medulloblastoma is one of the most common primary brain tumors in children and one of the rarest in adults [1, 2]. In the recent years, the results of the treatment have significantly improved by the use of combined therapy-surgery, craniospinal irradiation with dose escalation to the tumor bed or residual tumor, and, in children, chemotherapy [1-4]. The role of chemotherapy in the first-line treatment in adults is less clear due to increased risk of toxicity of systemic treatment. Recent studies of Rare Cancer Network Group showed that this group of patients may also benefit from systemic therapy [5]. But still, in this group it is used less frequently, usually in selected high-risk patients $[2,6]$. Five-year progression-free survival (PFS) in standard-risk patients is within the 
range of 57 to $82 \%$, and the 5 -year overall survival (OS) varies between 80 and $87 \%$, both in children and in young adult patients [1-6].

Despite the advances in treatment of patients with medulloblastoma and anaplastic ependymoma, there are still no clear guidelines concerning treatment of recurrence. The outcome is poor, irrespective of the implemented treatment methods (surgery, chemotherapy, combined in some cases with bone marrow transplantation, brachytherapy, radiosurgery, or hypofractionated stereotactic radiotherapy). So far, only two authors reported 5-year OS of 55-65\% [7-25].

Publications on the reirradiation of patients after radiotherapy of cerebrospinal axis are scarce, and radiotherapy is often not considered a salvage treatment because of its potential toxicity (including radiation necrosis of the brain), young age of patients, and uncertain effectiveness [5, 10-25].

We present a series of patients reirradiated in a single center and evaluate the treatment results and tolerance of radiosurgery (SRS)/hypofractionated stereotactic radiotherapy (SRT) implemented after craniospinal irradiation (CSI) in patients with a recurrent tumor.

\section{Material/methods}

\section{Group characteristics}

Study inclusion criteria were as follows: the diagnosis of a central nervous tumor, CSI as part of initial or second-line treatment, and treatment with SRS/SRT implemented after CSI. Fourteen consecutive patients ( 8 females, 6 males, median age at diagnosis of the disease was 22 years), diagnosed with medulloblastoma (MB, 10 patients), anaplastic ependymoma (AE, 3 patients), and primitive neuroectodermal tumor (PNET, 1 patient), met the inclusion criteria and were enrolled into the analysis. All patients received SRS or SRT as part of the treatment of recurrence after CSI. Information on patients and treatment details was collected retrospectively from patients' charts and treatment planning system archives.

\section{Primary treatment}

All patients were treated with radical intent. Before and during the primary treatment, all patients were in good performance status (ECOG $0-50 \%$, ECOG $1-50 \%$ of patients). Surgery was the primary treatment modality in all of them (in $63 \%$, gross total resection was performed, and in 3, partial resection). Primary tumor was located in posterior cranial fossa in 10 patients (MB patients); in 3, in frontal lobe; and in 1, in temporal lobe. Six patients (43\%) received adjuvant chemotherapy ( 5 with medulloblastoma, one with PNET). In 12 patients, CSI was a part of the primary treatment. Patients were irradiated with fraction dose of 1.5 to $1.8 \mathrm{~Gy}$ (median spinal fraction dose of $1.5 \mathrm{~Gy}$, median cranial fraction dose of $1.8 \mathrm{~Gy}$ ) to deliver the total dose of 30.6-36 Gy (median $36 \mathrm{~Gy}$ ) with boost to the tumor/tumor bed up to $53.9-60 \mathrm{~Gy}$ (median $54 \mathrm{~Gy}$ ). Additional unplanned surgery was performed in one patient after CSI due to aggravation of neurological symptoms. After the treatment, all patients were followed up in regional oncology centers. Patients had checkup visits every 3 to 6 months during the first 2 years after the primary treatment and every 6 months during the next years. Imaging was performed with similar consistency. Additional visits or imaging was performed when patient presented symptoms of tumor progression.

The details of the primary treatment employed in particular patients are presented in Table 1.

\section{Recurrence of the disease}

Recurrence of the disease occurred after the median time of 16 months (range 3 to 78 months) after the end of primary treatment. In all patients, diagnosis of the recurrence was based on MRI. The most common location of the recurrent tumor was primary site. Recurrent tumor was located in posterior cranial fossa in postoperative bed in 5 patients; in 5, in frontal lobe (in one of them in postoperative bed); in 2 , in temporal lobe (in postoperative bed in one); and in 2, close to the postoperative bed in parietal lobe and cribriform plate. Three patients were diagnosed with dissemination of the tumor (one in spinal canal), but all of them received chemotherapy afterwards and at the time of radiosurgery, no disease apart from the treated lesions was observed (MRI of craniospinal axis was performed to confirm that). One patient was treated for two lesions (both in the postoperative bed, close to each other, of $1.54 \mathrm{cc}$ and $0.76 \mathrm{cc}$ volume).

The majority of patients $(93 \%)$ were in good general condition at the time of diagnosis of the recurrence (ECOG 0 or 1 ), and $42 \%$ of them had no clinical symptoms of the recurrence. Headaches were the most commonly reported symptom (29\%). In 5 cases (36\%), resection of the recurrent tumor was performed. Six patients received systemic therapy. In two patients, conventional radiotherapy with fraction dose of 2 Gy to total dose of 20 (10 fractions) and 30 Gy (15 fractions), respectively, was delivered. In one of them, with AE, the surgical cavity after resection of the recurrent tumor was irradiated with 30 Gy. During the follow-up, a small lesion in the parietal region was found. Patient was referred to a neurosurgeon who did not decide to perform another surgery. Due to small size of the lesion (less than $2 \mathrm{~cm}$ ), the interdisciplinary board decided to treat the patient with SRS. The other patient, with PNET, was diagnosed with recurrence of the tumor in the ethmoid and nasal cavity. Due to large volume of the recurrent tumor, the first radiotherapy was delivered with conventional fractionation. Very good response to the first radiotherapy (regression of the irradiated lesion) led to the decision to additionally 
Table 1 Primary treatment in particular patients

\begin{tabular}{|c|c|c|c|c|c|c|c|}
\hline Patient & Histopathology & Primary tumor location & Age & Surgery & $\mathrm{CTH}$ & CSI & Total dose \\
\hline 1 & MB & Posterior cranial fossa & 3 & Non-radical surgery & Yes & No & - \\
\hline 2 & MB & Posterior cranial fossa & 4 & Radical surgery & Yes & Yes & $36 \mathrm{~Gy} /$ craniospinal axis, $54 \mathrm{~Gy} /$ tumor bed boost \\
\hline 3 & MB & Posterior cranial fossa & 9 & Non-radical surgery & Yes & Yes & 35.1 Gy/craniospinal axis, 55.1 Gy/tumor boost \\
\hline 4 & MB & Posterior cranial fossa & 10 & Non-radical surgery & Yes & Yes & 35.1 Gy/craniospinal axis, $55.1 \mathrm{~Gy} /$ tumor boost \\
\hline 5 & MB & Posterior cranial fossa & 22 & Non-radical surgery & - & Yes & $36 \mathrm{~Gy} /$ craniospinal axis, $60 \mathrm{~Gy} /$ tumor boost \\
\hline 6 & MB & Posterior cranial fossa & 30 & Radical surgery & - & No & - \\
\hline 7 & MB & Posterior cranial fossa & 31 & Radical surgery & - & Yes & $36 \mathrm{~Gy} /$ craniospinal axis, $54 \mathrm{~Gy} /$ tumor bed boost \\
\hline 8 & MB & Posterior cranial fossa & 46 & Non-radical surgery & - & Yes & 30.6 Gy/craniospinal axis, 53.9 Gy/tumor boost \\
\hline 9 & $\mathrm{AE}$ & Frontal lobe & 19 & Radical surgery & - & Yes & $36 \mathrm{~Gy} /$ craniospinal axis, $60 \mathrm{~Gy} /$ tumor bed boost \\
\hline 10 & $\mathrm{AE}$ & Frontal lobe & 34 & Radical surgery & - & Yes & $36 \mathrm{~Gy} /$ craniospinal axis, $60 \mathrm{~Gy} /$ tumor bed boost \\
\hline 11 & PNET & Frontal lobe & 32 & Non-radical surgery & Yes & Yes & 36 Gy/craniospinal axis, 54 Gy/tumor boost \\
\hline 12 & $\mathrm{AE}$ & Temporal lobe & 22 & Non-radical surgery & - & Yes & $36 \mathrm{~Gy} /$ craniospinal axis, $60 \mathrm{~Gy} /$ tumor boost \\
\hline 13 & MB & Posterior cranial fossa & 33 & Radical surgery & Yes & Yes & $36 \mathrm{~Gy} /$ craniospinal axis, $54 \mathrm{~Gy} /$ tumor bed boost \\
\hline 14 & MB & Posterior cranial fossa & 20 & Radical surgery & - & Yes & $36 \mathrm{~Gy} /$ craniospinal axis, $54 \mathrm{~Gy} /$ tumor bed boost \\
\hline
\end{tabular}

$A E$ anaplastic ependymoma, $C S I$ craniospinal irradiation, $C T H$ chemotherapy, $M B$ medulloblastoma, $P N E T$ primitive neuroectodermal tumor, $R T H$ radiotherapy

perform SRS. Another two patients received CSI at the time of recurrence (they did not receive that treatment before) after which they were qualified to radiosurgical treatment.

\section{Radiosurgery}

All patients received SRS or SRT as part of the treatment of the recurrence (two after CSI, as a boost on the recurrence site). Time between CSI and SRS/SRT of recurrence ranged from 1.1 to 75.6 months (median 6.2 months). During SRS/ SRT, all patients were immobilized with individualized thermoplastic masks covering head and shoulder region. Masks were fixed to the treatment couch during the treatment delivery in order to reduce patient's motion. Treatment planning was done with the BrainLab software and pencil beam optimization algorithm was used. All patients were treated with conventional linear accelerators equipped with a micromultileaf collimator. Radiation was delivered with conformal beam (10 patients) or intensity-modulated radiosurgery (IMRS; 4 patients) technique with 5 to 12 fields. The dose was normalized at the isocenter and planned to cover $98 \%$ of the target volume with $95 \%$ of the prescribed dose. Six to $20 \mathrm{MV}$ photons were used. Twelve patients received a single dose of 6-15 Gy (median 14.5 Gy). One patient received three fractions of $5 \mathrm{~Gy}$ and one six fractions of $5 \mathrm{~Gy}$. The youngest two patients ( 5 and 6 years old at the time of SRS) received short general anesthetic for the time of treatment delivery.

In all cases, recurrence was diagnosed based on MRI and clinicians engaged in the treatment of patients were able to use MRI to aid treatment planning. In all patients, the first radiotherapy treatment plans were reviewed in order to evaluate doses delivered to critical structures. This data was taken into account during the second course of irradiation. In 13 of 14 patients (including the four after resection), a recurrent tumor was visible on MRI and gross tumor volume (GTV) was defined as the contrast-enhancing lesion in T1-weighted images. In one patient, total resection of the recurrent tumor was performed and irradiated region covered the postoperative bed. There was no margin added and the planning target volume (PTV) was in fact GTV except the one patient mentioned above. PTV ranged from 0.54 to $27.04 \mathrm{cc}$ (median 1.36, mean 6.42). In case of hypofractionated stereotactic radiotherapy, the target volume definition did not differ from that used for single fraction treatment.

Treatment of the recurrence in particular patients is presented in Table 2.

After the radiosurgery, 12 patients were systematically followed up (2 did not come for planned checkup visit). Patients had checkup visits every 3 to 6 months during the first 2 years after the SRS/SRT and every 6 months during the next years. Imaging was performed with similar consistency. Additional visits or imaging was performed when patient presented symptoms of tumor progression. In all of them, treatment effect was assessed with diagnostic imaging (all patients had MRI and some of them CT but none of them had CT as a sole follow-up modality).

\section{Statistical analysis}

Statistica 12.0 was used for statistical analysis. The KaplanMeier method and log-rank test were used in statistical analysis. $p$ value of less than 0.05 was considered statistically significant. Follow-up was calculated from the date of the end of radiosurgery/hypofractionated stereotactic 
radiotherapy of the recurrent tumor to the date of death or (in case of alive patients) last contact. Progression was defined as the occurrence of a new lesion or progression of the irradiated tumor based on MRI imaging, and the date of MRI was defined as the date of progression. Progression-free survival was defined as a period of time without tumor progression or death. Data on the date of death were obtained from the National Cancer Registry.

\section{Results}

Local control (stabilization or regression of the lesion) was achieved in 9 patients $(75 \%)$-in 4 , complete regression, and in 5 patients, the size of the irradiated tumor was stable. Progression of the irradiated lesions was observed in 3 patients. Radiation-induced changes of surrounding healthy brain tissues (edema, vascular changes) were observed in all patients, but none of them developed radiation necrosis.

The treatment was well tolerated and no serious adverse effects were observed. Eleven patients were given steroids during hospitalization for SRS/SRT as a prevention of brain edema. Among them, four needed continuation of this treatment afterwards. In seven patients, headaches and symptoms of brain edema were observed during first weeks after reirradiation. All of them received steroids and in majority of them (except two with progression of the disease after SRS), the symptoms subsided. No seizures correlated with SRS were observed, and patients who previously suffered from epilepsy did not require modification of their standard treatment. No anesthetic complications or infections were observed. The majority of patients had no deterioration in performance status (ECOG 0 or 1-82\% during FU after SRS compared to $91 \%$ before SRS).

During follow-up, eight patients had disease progression within or outside the irradiated region (overall disease progression rate was $67 \%$, Fig. 1). Three patients had another surgery, five received systemic treatment, and four received radiotherapy. Fraction dose ranged from 2 to 6 Gy and total dose was within 9 to $18 \mathrm{~Gy}$. One patient received 3 fractions of 3 Gy (total dose, TD 9 Gy), two 3 fractions of 6 Gy (TD $18 \mathrm{~Gy}$ ), and one was irradiated with fraction dose of $2 \mathrm{~Gy}$ to TD of 18 Gy.

During the study period, eleven patients died. The followup for the 3 patients still alive was 6.7, 40.5, and 41.4 months, respectively. One- and 2-year overall survival (OS) was 70\% and 39\% (Fig. 1). Unfortunately, neither National Cancer Registry nor Regional Civil Registry offices provide with the information about the cause of death, and we decided not to call families of the patients due to ethical reasons.

Patients in ECOG performance status of 0 at the time of diagnosis of the disease tended to have better 2-year OS compared to patients in ECOG performance status 1-68\% vs. $14 \%$
( $p=0.057$, Fig. 2). Patients in ECOG 0 at the time of diagnosis of the recurrence tended to have better OS compared to those in ECOG 1, but the difference was not statistically significant $(p=0.09$, Fig. 3).

\section{Discussion}

CNS reirradiation, especially in children, is rarely used due to concerns of its possible toxicity [10, 26-28]. It is not a standard treatment, but in patients with recurrent MB after multimodal therapy (surgery, CSI, CTH), there is a lack of established standards [16]. The results of recent studies on patients with recurrence who received various multidrug chemotherapies, high-dose chemotherapy with bone marrow transplantation combined with surgery, or other treatment options are still poor, and cure is rare $[7-9,16,22,23]$.

The number of publications concerning reirradiation after CSI is small, and the number of patients described in all the reports does not exceed 300 cases [12-25].

Studies on reirradiation of patients who received radiotherapy of cerebrospinal axis as the first-line treatment are shown in Table 3.

The group of patients treated in our center is small, although comparable to the groups described in the literature. Some patients presented in publications concerning reirradiation of CNS received conventional radiotherapy, and the doses used were within the range of 18 to $70 \mathrm{~Gy}(1.2-$ 2.0 Gy per fraction). Patients who received radiosurgery or hypofractionated stereotactic radiotherapy were treated with the total dose of 12-24 Gy (radiosurgery) to 24-40 Gy (stereotactic radiotherapy) [12-23]. Total doses used in our hospital were similar to those reported in the literature and were within the range of 6 to $30 \mathrm{~Gy}$ (median $15 \mathrm{~Gy}$ ).

With introduction of new WHO Classification of Central Nervous System Tumors in 2017, primitive neuroectodermal tumors are no longer recognized [29]. The patient with PNET in our series was diagnosed in 2005 and died in 2008, and we were not able to reevaluate histopathologic samples according to the new system. As optimal integration of this newly developed system into clinical care is still a matter of active debate and the purpose of the study was the evaluation of efficacy and toxicity of reirradiation in patients who previously underwent craniospinal irradiation, we included that patient into analysis.

Meta-analysis concerning reradiation of patients with recurrent glial tumors showed that in case of irradiation to the normalized total dose of less than $100 \mathrm{~Gy}$, the risk of radiation necrosis of the brain is very low [30]. The results of radiobiological research on cells of the nervous system suggested that partial repair of radiation damage can occur in the central nervous system. Publications concerning neurotoxicity indicate that factors such as maximum tumor diameter, general 


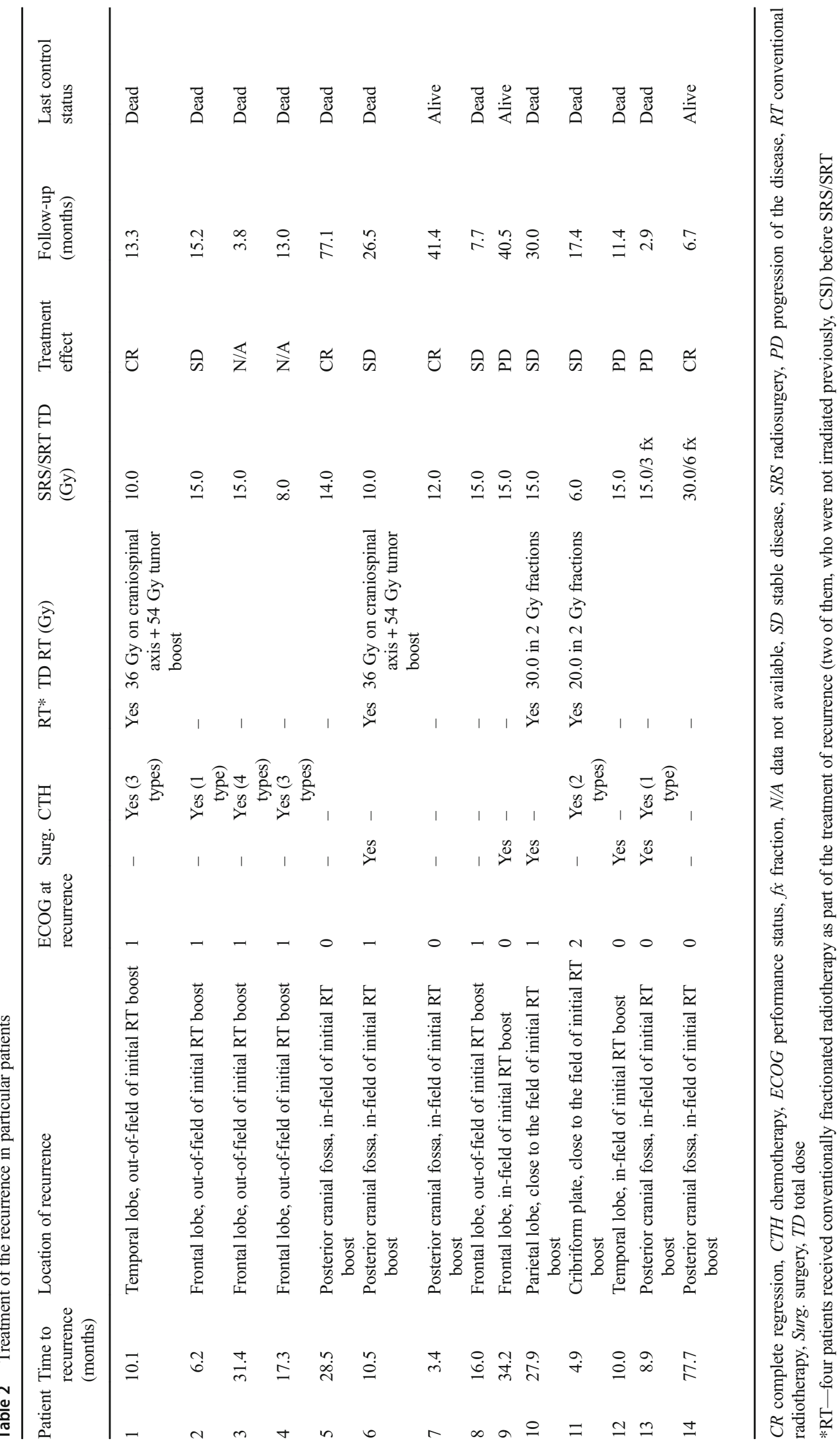


Fig. 1 Overall survival and progression-free survival

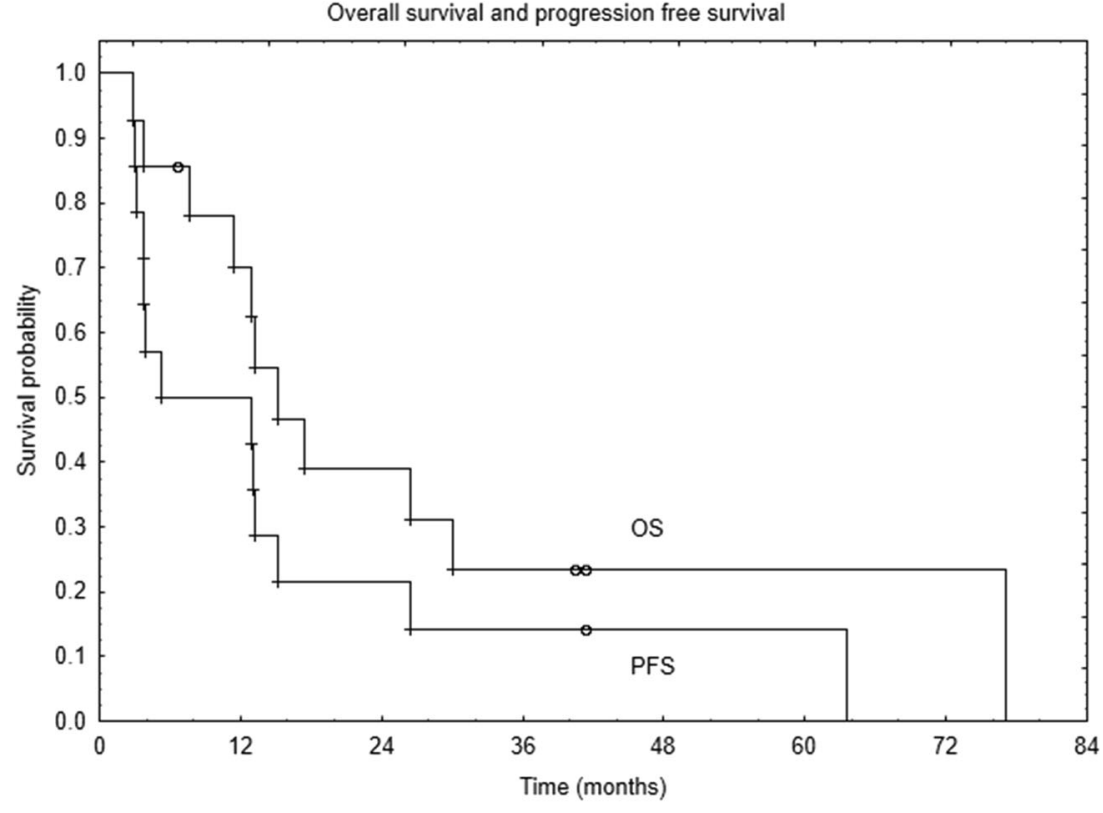

condition, dose delivered to the tumor, or use of chemotherapy have an effect on its occurrence [10,30]. These data suggest that reirradiation may be considered in carefully selected patients without increased risk of complications.

The published reports describe lack or low toxicity of reirradiation and good tolerance of the treatment itself [11-22, 26-28]. Necrosis in the irradiated field, observed by Bakst, is in fact not an undesirable event if area of the necrosis is within the tumor and does not encompass the uninvolved brain [15]. Nevertheless, no patient in our series developed radiation necrosis after radiosurgery, which is consistent with observations of other researches. Results of our study suggesting that patients in better performance status at the time of diagnosis of the disease tended to have better overall survival could be a valuable information of possible outcome.

In the available literature, 5-year OS of patients who underwent reirradiation after CSI ranged from 20 to $65 \%$ and median OS is within the range of 10 to 73 months [11-23]. These data are, however, difficult to interpret because some researchers reported their results in relation to the date of recurrence and part in relation to the date of salvage therapy. The described treatment regimens vary widely, like in our series, and some of the patients were given concurrent or adjuvant systemic therapy. The results of our study, i.e., 2year OS of $39 \%$ in comparison to the reported 2-year OS of approximately $25 \%$, showed that some patients might benefit
Fig. 2 Survival curves according to patients' performance status at the time of diagnosis of the disease

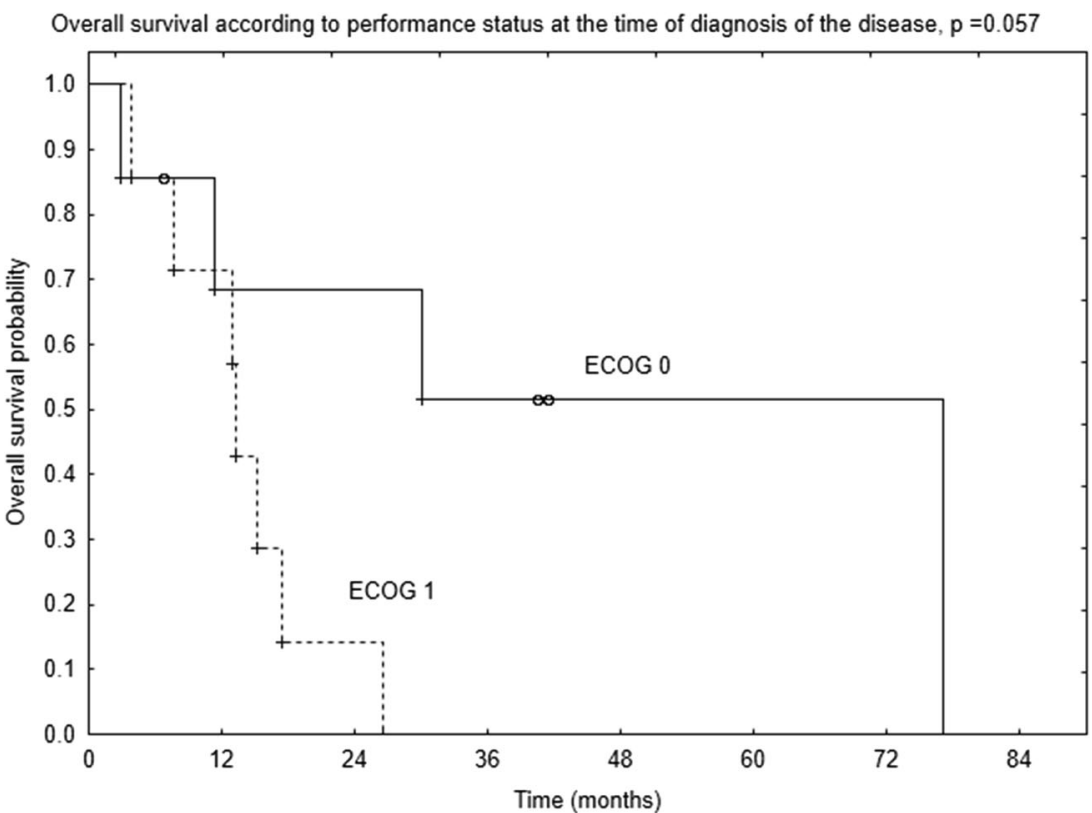


Fig. 3 Survival curves according to patients' performance status at the time of diagnosis of the recurrence
Overall survival according to performance status at the time of diagnosis of the recurrence, $p=0.09$

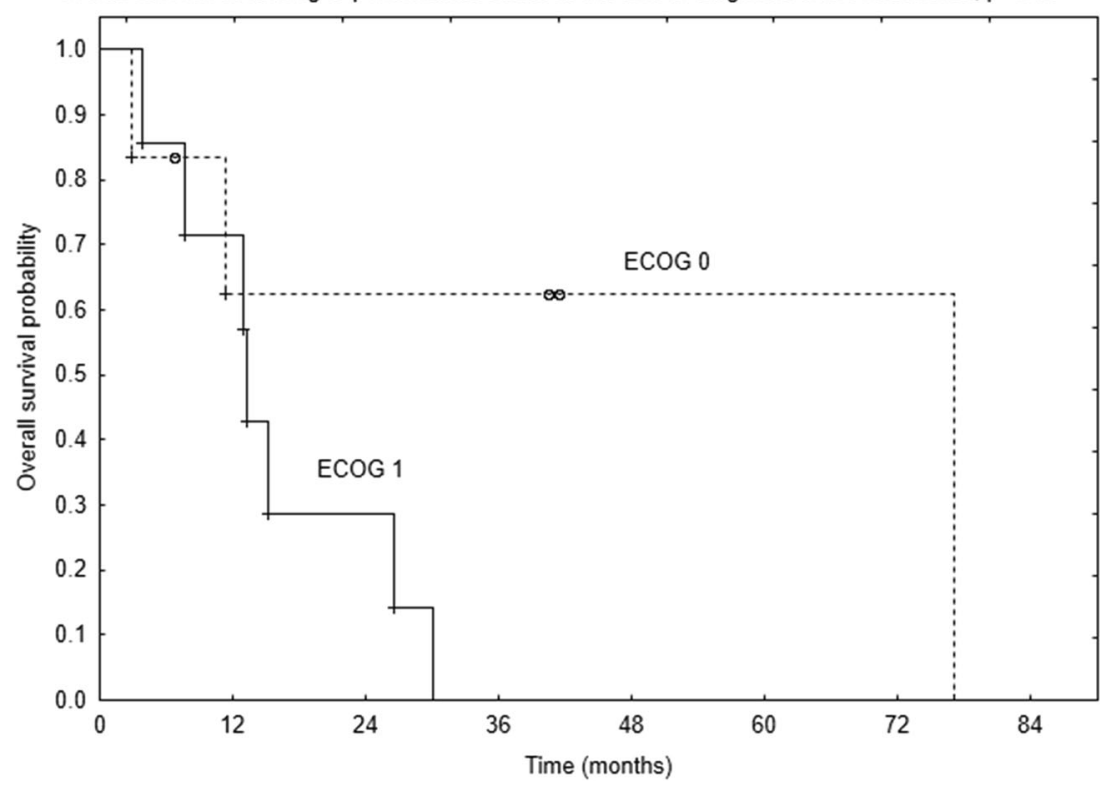

from reirradiation [23]. Also, Dunkel et al. reported an improvement in local control when radiotherapy was added to the treatment of the recurrence [8]. Similar observations could be noticed in our series - more than $70 \%$ of patients achieved local control in the irradiated volume.

The patients with MB, especially children, are more likely to receive chemotherapy than patients with ependymoma, and the biology of those two tumors differs. What is more, pediatric oncologists are more willing to give another course of chemotherapy than to refer second radiotherapy. As a result, some of the patients in our series received even up to 3 different types of systemic treatment before salvage radiotherapy. Undoubtedly, with more aggressive and less responsive to the treatment disease, even with very precise SRS, the results will be poor. Whether gaining local control with radiosurgery implemented first and chemotherapy used as an adjuvant treatment would give

Table 3 Publications on reirradiation after craniospinal irradiation [10-23, 25]

\begin{tabular}{|c|c|c|c|c|}
\hline Study & $\begin{array}{l}\text { Number of } \\
\text { patients }\end{array}$ & Doses applied in salvage treatment & 5-year overall survival & Toxicity of salvage treatment \\
\hline Rao AD et al. [25] & 67 & $\begin{array}{l}\text { 18.6-70.1 Gy (median 53.1) } \\
\text { median fd } 1.8 \text { Gy }\end{array}$ & $\begin{array}{l}\text { Median OS MB, } 8.4 \text { months; ependymoma, } \\
20.5 \text { months; whole group 5-year OS, 35\% }\end{array}$ & 1 case of radionecrosis \\
\hline Wetmore et al. [16] & 38 & Mean TD of 38 Gy (range 18-54 Gy) & $\begin{array}{l}5 \text {-year OS, } 55 \% \pm 14 \% ; 10 \text {-year OS, } 33 \% \pm 16 \% \\
\text { (from the date of recurrence) }\end{array}$ & Increased incidence of necrosis \\
\hline Bakst et al. [15] & 13 & TD 30 Gy, fd 1.5 Gy & $\begin{array}{l}5 \text {-year OS } 65 \% \text { (from the date of recurrence), } \\
12 \text { patients received CTH; median OS } 37 \text { months }\end{array}$ & 1 case of asymptomatic, in-field necrosis \\
\hline Saran et al. [17] & 14 & TD $30-40$ Gy in $6-8$ fractions & 5 -year OS, $20 \%$; median OS, 29 months & No toxicity. \\
\hline Abe et al. [11] & 12 & $\begin{array}{l}\text { Median peripheral TD } 20 \mathrm{~Gy} \\
\quad \text { (normalization on isodose } 50 \% \text { ) }\end{array}$ & $\begin{array}{l}\text { 2-year OS, } 33 \% \pm 14 \% ; 3 \text {-year OS, } 25 \% \pm 13 \% \\
\quad \text { (all patients received CTH after SRT, } 5+\text { PBSCT); } \\
\text { median OS, } 19 \text { months }\end{array}$ & $\begin{array}{l}1 \text { case of brainstem edema, } 1 \\
\text { patient died due to toxicity } \\
\text { of CTH }\end{array}$ \\
\hline Massimino et al. [23] & 17 & $\begin{array}{l}7 \text { patients TD } 20.2 \mathrm{~Gy}, \mathrm{fd} 1.3 \mathrm{~Gy}, 3 \\
\text { patients TD } 50 \mathrm{~Gy}\end{array}$ & $\begin{array}{l}\text { 10/17 received RT, all HD CTH } \pm \text { PBSCT; for whole } \\
\text { group: } 5 \text {-year OS } 20 \% \text {, median OS } 41 \text { months }\end{array}$ & Not reported for RT \\
\hline Bauman et al. [10] & 14 & Not specified for MB & Median OS 11.5 months & No radiation necrosis \\
\hline Chojnacka et al. [19] & 6 & TD 40 Gy, fd 2 Gy & $\begin{array}{l}\text { Median OS } 17.5 \text { months, } 1 \text { death during FU } \\
\text { ( } 83 \% \text { alive) }\end{array}$ & No grade $3-5$ toxicity \\
\hline Milker-Zabel et al. [20] & 20 & Mean TD 24 Gy (SRT) or 15 Gy (SRS) & 6-year OS, 35\%; median OS, 73 months & No late toxicity \\
\hline Patrice et al. [12] & 14 & Median min. TD 12 Gy & $\begin{array}{l}\text { 2-year OS } 45 \%, 13 \text { patients received CTH; } \\
\text { median OS } 10 \text { months }\end{array}$ & No radiation necrosis \\
\hline Padovani et al. [22] & 5 & TD 28 Gy, fd 1.8 Gy & $\begin{array}{l}\text { All: concomitant temozolomide, } 80 \% \text { alive } \\
\text { after mean FU of } 25 \text { months }\end{array}$ & No neurologic toxicity \\
\hline Bugulione et al. [13] & 1 & TD 52.8 Gy, fd 1.2 Gy/twice a day & Alive after 18 months & No radiation necrosis \\
\hline Keshavarzi et al. [18] & 1 & TD 14 Gy in 1 fraction & Alive after 12 months & No toxicity \\
\hline Privitera et al. [21] & 1 & TD 24 Gy & $\begin{array}{l}\mathrm{CTH}+\text { bevacizumab died with disease after } \\
35 \text { months }\end{array}$ & No radiation necrosis \\
\hline Cieślak et al. [14] & 1 & TD 45 Gy, fd 1.8 Gy & Alive after 15 months & No toxicity \\
\hline
\end{tabular}

$C T H$ chemotherapy, $f d$ fraction dose, $F U$ follow-up, $H D$ high dose, min. minimum, $O S$ overall survival, PBSCT peripheral blood stem cell transplantation, $R T$ radiotherapy, $S R S$ stereotactic radiosurgery, $S R T$ stereotactic radiotherapy, $T D$ total dose 
better results than irradiation after exhaustion of possibilities of systemic treatment remains an open question.

There are several limitations of our study: heterogeneous histopathological diagnoses (MB, AE), lack of histopathologic and molecular feature description, and heterogeneous patient population (children and adults) who received SRS/SRT during the long period of 13 years. Furthermore, the recommendation of treatment of anaplastic ependymoma changed in the last years and CSI is no longer standard of treatment in those patients.

\section{Conclusions}

Stereotactic radiosurgery or hypofractionated stereotactic radiotherapy is an effective treatment method of the local recurrence after CSI. It allows for achieving good local response and can be performed safely in heavily pre-treated patients.

\section{Compliance with ethical standards}

All procedures performed in studies involving human participants were in accordance with the ethical standards of the institutional and/or national research committee and with the 1964 Helsinki Declaration and its later amendments or comparable ethical standards.

This article does not contain any studies with animals performed by any of the authors.

Conflict of interest On behalf of all authors, the corresponding author states that there is no conflict of interest.

Open Access This article is distributed under the terms of the Creative Commons Attribution 4.0 International License (http:// creativecommons.org/licenses/by/4.0/), which permits unrestricted use, distribution, and reproduction in any medium, provided you give appropriate credit to the original author(s) and the source, provide a link to the Creative Commons license, and indicate if changes were made.

Publisher's Note Springer Nature remains neutral with regard to jurisdictional claims in published maps and institutional affiliations.

\section{References}

1. Lannering B, Rutkowski S, Doz F, Pizer B, Gustafsson G, Navajas A, Massimino M, Reddingius R, Benesch M, Carrie C, Taylor R, Gandola L, Björk-Eriksson T, Giralt J, Oldenburger F, Pietsch T, Figarella-Branger D, Robson K, Forni M, Clifford SC, WarmuthMetz M, von Hoff K, Faldum A, Mosseri V, Kortmann R (2012) Hyperfractionated versus conventional radiotherapy followed by chemotherapy in standard-risk medulloblastoma: results from the randomized multicenter HIT-SIOP PNET 4 trial. J Clin Oncol 30: 3187-3193. https://doi.org/10.1200/JCO.2011.39.8719

2. Call JA, Naik M, Rodriguez FJ, Giannini C, Wu W, Buckner JC, Parney IF, Laack NN (2014) Long-term outcomes and role of chemotherapy in adults with newly diagnosed medulloblastoma. Am J Clin Oncol 37:1-7. https://doi.org/10.1097/COC. 0b013e31826b9cf0
3. von Bueren AO, von Hoff K, Pietsch T, Gerber NU, Warmuth-Metz M, Deinlein F, Zwiener I, Faldum A, Fleischhack G, Benesch M, Krauss J, Kuehl J, Kortmann RD, Rutkowski S (2011) Treatment of young children with localized medulloblastoma by chemotherapy alone: results of the prospective, multicenter trial HIT 2000 confirming the prognostic impact of histology. Neuro-Oncology 13:669-679. https://doi.org/10.1093/neuonc/nor025

4. Packer RJ, Zhou T, Holmes E, Vezina G, Gajjar A (2013) Survival and secondary tumors in children with medulloblastoma receiving radiotherapy and adjuvant chemotherapy: results of Children's Oncology Group trial A9961. Neuro-Oncology 15:97-103. https://doi.org/10.1093/neuonc/nos267

5. Atalar B, Ozsahin M, Call J, Napieralska A, Kamer S, Villa S, Erpolat P, Negretti L, Lassen-Ramshad Y, Onal C, Akyurek S, Ugurluer G, Baumert BG, Servagi-Vernat S, Miller RC, Ozyar E, Sio TT (2018) Treatment outcome and prognostic factors for adult patients with medulloblastoma: the Rare Cancer Network (RCN) experience. Radiother Oncol 127:96-102. https://doi.org/10.1016/j. radonc.2017.12.028

6. Brandes AA, Franceschi E (2014) Shedding light on adult medulloblastoma: current management and opportunities for advances. Am Soc Clin Oncol Educ Book:e82-e87. https://doi.org/10. 14694/EdBook_AM.2014.34.e82

7. Park JE, Kang J, Yoo KH, Sung KW, Koo HH, Lim DH, Shin HJ, Kang HJ, Park KD, Shin HY, Kim IH, Cho BK, Im HJ, Seo JJ, Park HJ, Park BK, Ahn HS (2010) Efficacy of high-dose chemotherapy and autologous stem cell transplantation in patients with relapsed medulloblastoma: a report on the Korean Society for Pediatric Neuro-Oncology (KSPNO)-S-053 study. J Korean Med Sci 25: 1160-1166. https://doi.org/10.3346/jkms.2010.25.8.1160

8. Dunkel IJ, Gardner SL, Garvin JH Jr, Goldman S, Shi W, Finlay JL (2010) High-dose carboplatin, thiotepa, and etoposide with autologous stem cell rescue for patients with previously irradiated recurrent medulloblastoma. Neuro-Oncology 12:297-303. https://doi. org/10.1093/neuonc/nop031

9. Gururangan S, Krauser J, Watral MA, Driscoll T, Larrier N, Reardon DA, Rich JN, Quinn JA, Vredenburgh JJ, Desjardins A, McLendon RE, Fuchs H, Kurtzberg J, Friedman HS (2008) Efficacy of high-dose chemotherapy or standard salvage therapy in patients with recurrent medulloblastoma. Neuro-Oncology 10: 745-751. https://doi.org/10.1215/15228517-2008-044

10. Bauman GS, Sneed PK, Wara WM, Stalpers LJ, Chang SM, McDermott MW, Gutin PH, Larson DA (1996) Reirradiation of primary CNS tumors. Int J Radiat Oncol Biol Phys 36:433-441

11. Abe M, Tokumaru S, Tabuchi K, Kida Y, Takagi M, Imamura J (2006) Stereotactic radiation therapy with chemotherapy in the management of recurrent medulloblastomas. Pediatr Neurosurg 42:81-88

12. Patrice SJ, Tarbell NJ, Goumnerova LC, Shrieve DC, Black PM, Loeffler JS (1995) Results of radiosurgery in the management of recurrent and residual medulloblastoma. Pediatr Neurosurg 22: 197-203

13. Buglione M, Triggiani L, Grisanti S, Liserre R, Buttolo L, Gipponi S, Bonetti F, Todeschini A, Spiazzi L, Magrini SM (2013) Retreatment of recurrent adult medulloblastoma with radiotherapy: a case report and review of the literature. J Med Case Rep 7:64. https://doi.org/10.1186/1752-1947-7-64

14. Cieślak E, Kepka L, Fijuth J, Marchel A, Kroh H (2004) Very late relapse of medulloblastoma. Folia Neuropathol 42:49-53

15. Bakst RL, Dunkel IJ, Gilheeney S, Khakoo Y, Becher O, Souweidane MM, Wolden SL (2011) Reirradiation for recurrent medulloblastoma. Cancer 117:4977-4982. https://doi.org/10. $1002 /$ cncr. 26148

16. Wetmore C, Herington D, Lin T, Onar-Thomas A, Gajjar A, Merchant TE (2014) Reirradiation of recurrent medulloblastoma: 
does clinical benefit outweigh risk for toxicity? Cancer 120:37313737. https://doi.org/10.1002/cncr.28907

17. Saran F, Baumert BG, Creak AL, Warrington AP, Ashley S, Traish D, Brada M (2008) Hypofractionated stereotactic radiotherapy in the management of recurrent or residual medulloblastoma/PNET. Pediatr Blood Cancer 50:554-560

18. Keshavarzi S, Meltzer H, Ben-Haim S, Newman CB, Lawson JD, Levy ML, Murphy K (2009) Initial clinical experience with frameless optically guided stereotactic radiosurgery/radiotherapy in pediatric patients. Childs Nerv Syst 25:837-844. https://doi. org/10.1007/s00381-009-0840-8

19. Chojnacka M, Skowrońska-Gardas A, Pędziwiatr K, MorawskaKaczyńska M, Perek M, Perek D (2011) Reirradiation of relapsed brain tumors in children. Rep Pract Oncol Radiother 17:32-37. https://doi.org/10.1016/j.rpor.2011.10.004

20. Milker-Zabel S, Zabel A, Thilmann C, Zuna I, Hoess A, Wannenmacher M, Debus J (2002) Results of three-dimensional stereotactically-guided radiotherapy in recurrent medulloblastoma. J Neuro-Oncol 60:227-233

21. Privitera G, Acquaviva G, Ettorre GC, Spatola C (2009) Antiangiogenic therapy in the treatment of recurrent medulloblastoma in the adult: case report and review of the literature. J Oncol 2009:247873. https://doi.org/10.1155/2009/247873

22. Padovani L, Andre N, Gentet JC, Figarella Branger D, Scavarda D, Verschuur A, Chinot O, Cowen D, Muracciole X (2011) Reirradiation and concomitant metronomic temozolomide: an efficient combination for local control in medulloblastoma disease? J Pediatr Hematol Oncol 33:600-604. https://doi.org/10.1097/MPH. 0b013e3182331 eaf

23. Massimino M, Gandola L, Spreafico F, Biassoni V, Luksch R, Collini P, Solero CN, Simonetti F, Pignoli E, Cefalo G, Poggi G, Modena P, Mariani L, Potepan P, Podda M, Casanova M, Pecori E, Acerno S, Ferrari A, Terenziani M, Meazza C, Polastri D, Ravagnani F, Fossati-Bellani F (2009) No salvage using highdose chemotherapy plus/minus reirradiation for relapsing previously irradiated medulloblastoma. Int J Radiat Oncol Biol Phys 73:1358-1363. https://doi.org/10.1016/j.ijrobp.2008.06.1930

24. Massimino M, Casanova M, Polastri D, Biassoni V, Modena P, Pecori E, Schiavello E, De Pava MV, Indini A, Rampini P, Bauer D, Catania S, Podda M, Gandola L (2013) Relapse in medulloblastoma: what can be done after abandoning high-dose chemotherapy? A mono-institutional experience. Childs Nerv Syst 29:1107-1112. https://doi.org/10.1007/s00381-013-2104-x

25. Rao AD, Rashid AS, Chen Q, Villar RC, Kobyzeva D, Nilsson K, Dieckmann K, Nechesnyuk A, Ermoian R, Alcorn S, MacDonald SM, Ladra MM, Ford EC, Winey BA, Figueiredo MLS, Chen MJ, Terezakis SA (2017) Reirradiation for recurrent pediatric central nervous system malignancies: a multi-institutional review. Int J Radiat Oncol Biol Phys 99:634-641. https://doi.org/10.1016/j. ijrobp.2017.07.026

26. Larysz D, Blamek S, Larysz P, Pietras K, Mandera M (2010) Posterior fossa brain tissue injury: developmental, neuropsychological, and neurological consequences of brain tumors in children. Acta Neurochir Suppl 106:271-274. https://doi.org/10.1007/9783-211-98811-4 51

27. Blamek S, Larysz D, Ficek K, Sokół M, Miszczyk L, Tarnawski R (2010) MR spectroscopic evaluation of brain tissue damage after treatment for pediatric brain tumors. Acta Neurochir Suppl 106: 183-186. https://doi.org/10.1007/978-3-211-98811-4_33

28. Boguszewicz L, Blamek S, Sokół M (2010) Pattern recognition methods in (1)H MRS monitoring in vivo of normal appearing cerebellar tissue after treatment of posterior fossa tumors. Acta Neurochir Suppl 106:171-175. https://doi.org/10.1007/978-3-21198811-4 31

29. Wen PY, Huse JT (2017) 2016 World Health Organization classification of central nervous system tumors. Continuum (Minneap Minn) 23:1531-1547. https://doi.org/10.1212/CON. 0000000000000536

30. Mayer R, Sminia P (2008) Reirradiation tolerance of the human brain. Int J Radiat Oncol Biol Phys 70:1350-1360 